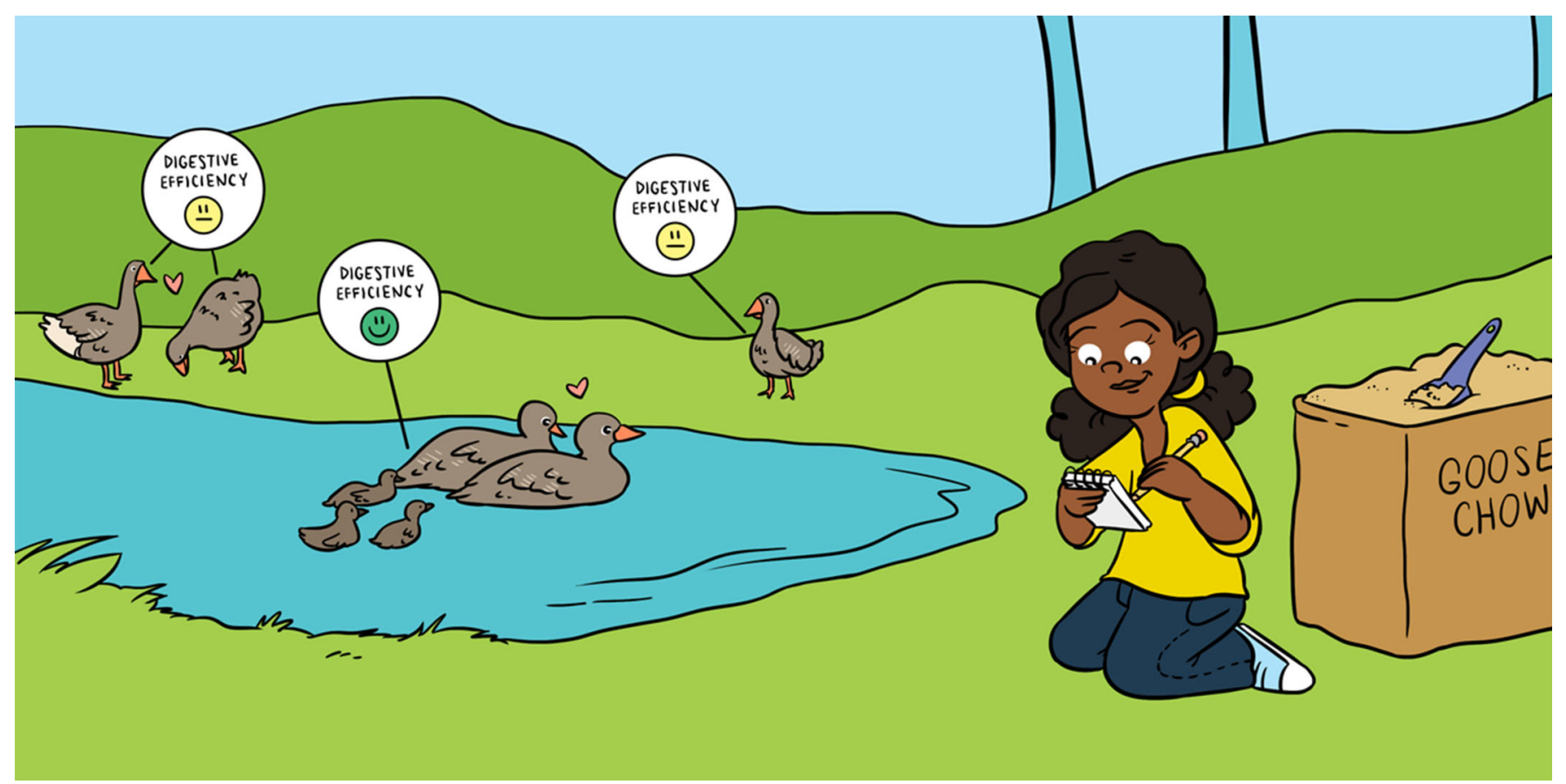

\title{
HOW HAVING A FAMILY IMPROVES DIGESTION IN SOCIAL GEESE
}

\author{
Gudrun Gegendorfer ${ }^{1}$ and Didone Frigerio ${ }^{1,2^{*}}$ \\ ${ }^{1}$ Konrad Lorenz Research Center for Behaviour and Cognition, University of Vienna, Vienna, Austria \\ ${ }^{2}$ Department of Behavioral and Cognitive Biology, University of Vienna, Vienna, Austria
}

\section{YOUNG REVIEWER:}

FRESIA

AGE: 11
As a human being, having family and friends helps us in many ways. Animal societies are not much different: a stable social environment is essential for the health of the body. Among birds, graylag geese are highly social. Therefore, they are a very good example for studying the benefits of living in groups. In this study, we looked at the quality of the digestion and the breeding success of 38 free-living graylag geese. The birds were individually tagged and belonged to different social categories. The categories were pairs with offspring, pairs without offspring, and unpaired birds. We found that individuals that have stable social relationships with their family members have better digestion and are more likely to breed successfully in the following breeding season. These are new insights into the benefits of social life in birds.

\section{STUDYING SOCIAL INTERACTIONS IN GRAYLAG GEESE}

Have your parents ever told you to eat your peas? Have your parents ever cooked your favorite meal because they knew you would like it? 
If so, then your health has probably benefited from being in a family. You and the rest of your family benefit nutritionally from the care you give each other. It turns out that the same thing happens in animal families and/or societies, where the social position of an individual animal affects its life in many ways. For instance, whether an animal has a mate or not may influence how much power it has within the group. Additionally, the social position of an individual within the group affects its behavior when feeding and therefore how much and what kind of food it gets to eat [1]. Generally, the dominant individuals in a group are faster at getting access to food and more motivated to defend food resources as compared to low-ranking individuals. This means that high-ranking individuals in the group have access to larger quantities of food, which is often of high quality, too. In addition, a high rank is often linked to better reproduction, lower stress [2], and good digestion [3].

Among birds, graylag geese (Anser anser) are highly social. These geese have been extensively studied and are an ideal species to use for research about social interactions in animals. They live in big flocks for most of the year and pair-partners (male and female) usually stay together for several years, similar to the way humans form couples. Paired birds often stay close to each other during the day no matter what they are doing, for example feeding or resting. After short separations, or simply when they get excited (when other geese are fighting, for example) they greet each other to show that they belong together. Furthermore, graylag geese have strong family ties. Goslings, which are young geese, stay close to their parents from hatching until the next breeding season, which means at least 1 year.

As in human society, disputes between pairs, families, and clans are common within flocks. Conflicts produce social instability and stress. However, a so-called social partner, which could be a mate, one of the parents, or a sibling, can reduce the stress caused by disputes in the social environment and improve the well-being of an individual. To investigate the relationship between the social environment and

DIGESTIVE EFFICIENCY

The proportion of eaten food that gets broken down for use by the body. an individual's well-being, we looked at digestive efficiency. This measurement tells us how much of the food that was eaten was broken down for use by the body. We expected social relationships to affect digestive efficiency in graylag geese.

\section{WHAT DID WE INVESTIGATE?}

We studied a group of graylag geese to find out if and how digestive efficiency and social environment, such as being paired or not, or having offspring or not, are related to each other. The study was conducted in February, when the ground was fully covered with snow and the geese were only able to feed on the food we provided. In this way, we regulated the quantity and quality of the food available. 


\section{BREEDING SUCCESS}

The number of hatched eggs.

1 https://klf.univie.ac.at/

\section{DROPPINGS}

The equivalent of feces and urine in mammals. In birds, they are eliminated together in the droppings.

\section{DEFECATION}

A nice way of saying "going poop."
First, we hypothesized that paired birds with offspring would have a better digestive efficiency than unpaired individuals. We considered the digestive efficiency to be an indicator of nutrition and therefore also of the overall body condition of an individual. At the end of winter, when these data were collected and the breeding season starts, an individual's body condition will play a major role with respect to reproduction. Animals with healthy bodies will be more likely to have offspring. Therefore, as a second hypothesis, we expected digestive efficiency to be related to breeding success.

\section{WHERE ARE THE BIRDS WE STUDIED?}

The study was conducted at the Konrad Lorenz Research Center ${ }^{1}$ in the valley of the river Alm in the northern part of the Austrian Alps, which are located in central Europe. A non-migratory flock of graylag geese was introduced there by Konrad Lorenz in 1973. The birds are free to move and fly around and generally spend their time close to the research center, where they are provided with food twice a day, all year round. All geese are tagged with colored rings on their legs and are used to the close presence of humans. Data about every individual goose has been collected since 1973, and therefore we know the friends and relatives of each bird in the flock.

\section{HOW DID WE STUDY DIGESTIVE EFFICIENCY IN GEESE?}

During the period of data collection, the flock consisted of 167 individuals. Droppings from 38 individuals (20 males and 18 females) belonging to different social categories within the flock (paired with and without offspring, unpaired individuals, and juveniles) were collected during 9 consecutive days in winter 2017. During this period, the snowpack forced the birds to feed exclusively on the pellets we provided, which were made out of a mix of cereals, dried herbs, and grasses. In sum, 184 droppings were collected immediately after defecation (pooping) and were frozen at $-20^{\circ} \mathrm{C}$ within $1 \mathrm{~h}$, until further analysis.

To find out how efficiently the geese digested their food, both the food pellets and the droppings were analyzed by drying them in ovens and a test was performed to determine how much lignin was in them. Lignin is an indigestible plant component. Since lignin cannot be digested, it can be used as a natural marker providing information about the quantity of food ingested, assimilated and ejected (Figure 1). We then calculated the digestive efficiency of the geese using this equation: digestive efficiency $(\%)=[(1-$ lignin in pellets $) /$ lignin in droppings $] \times$ 100. This equation tells us which percentage of the ingested food was also retained in the body. 
Figure 1

To calculate the digestive efficiency of the graylag geese, we measured the proportion of lignin (the white dots), an indigestible plant component, both in the food and in the droppings of the graylag geese. This tells us what proportion of the ingested food the goose was able to utilize. Credits: Helene Vesely.

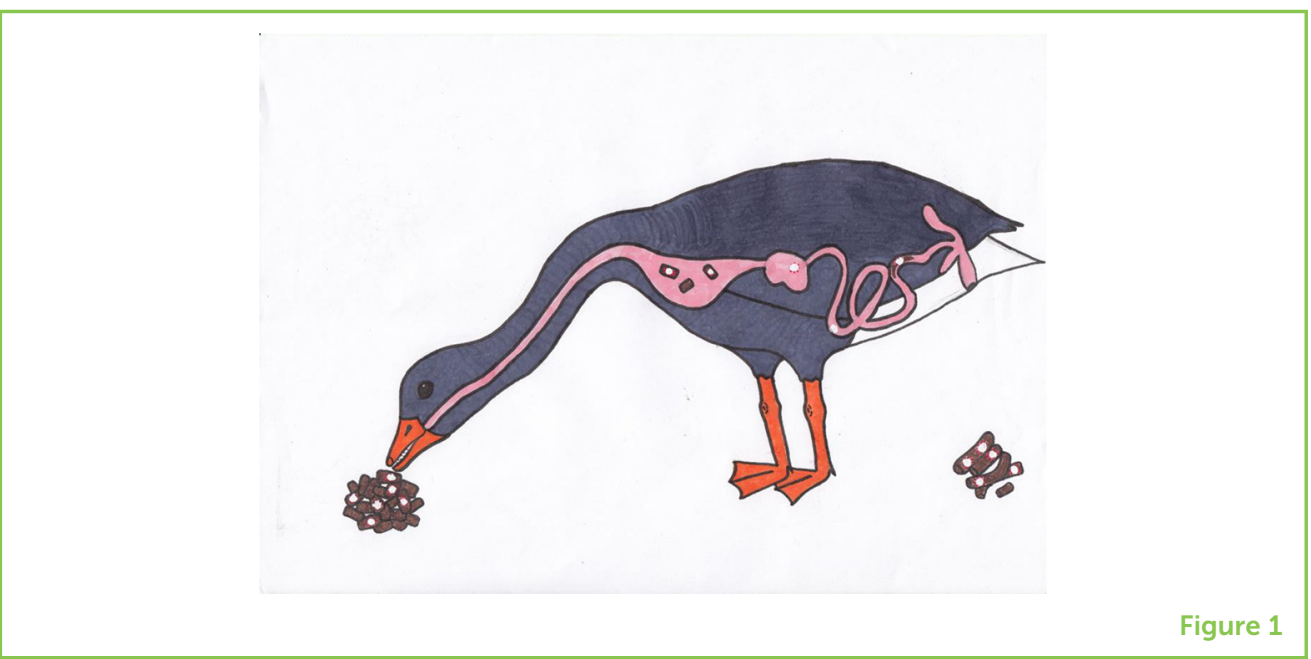

\section{WHAT DID WE FIND AND WHAT DO OUR RESULTS MEAN?}

As expected, our results showed that social environment fine-tunes digestive efficiency. Paired individuals with offspring showed better digestive efficiency than paired individuals without offspring or unpaired birds (Figure 2). Additionally, the results suggest that individuals with stable social relationships had better digestive efficiency. We think that pairs with offspring benefit because the juveniles also help to look out for potential challenges, allowing the parents (or the entire family) to spend more time feeding. It is known from other goose species that long-lasting family ties are beneficial for both offspring and parents. For instance, young barnacle geese living in family units were less disturbed during feeding than those who had left the family unit [4]. The juveniles considered in our study were already 2 years of age and were no longer spending time with their parents. Nevertheless, they had a high digestive efficiency, which suggests that other factors are involved in the relationship between social environment and digestive efficiency. For instance, juvenile graylag geese may be comparable to adolescent humans, who are hungry all the time and do not really get fat, because they efficiently direct their food resources into growth.

Our study also showed that geese that hatched offspring in the breeding season following the data collection period showed higher digestive efficiency than those failing to hatch goslings (Figure 3). The egg-laying period, which starts at the end of winter, is energetically very demanding. Just consider that a female goose weighs $\sim 3 \mathrm{~kg}$, one goose egg weighs $\sim 170 \mathrm{~g}$ and a female lays on average six eggs, which means about $1 \mathrm{~kg}$ of her body mass. Therefore, it might be essential for a goose, at the beginning of the breeding season, to be efficient in digesting food, to provide enough energy to lay eggs. However, we are still not sure if there is a direct cause/effect relationship between 
Figure 2

Differences in percentages of digestive efficiency between geese from different social categories. You can see that paired individuals with offspring showed better digestive efficiency than paired individuals without offspring or unpaired birds. The results suggest that individuals with stable social relationships had better digestive efficiency.

Figure 3

Differences in percentages of digestive efficiency between individuals with hatchlings and those without in the season following the study. You can see that geese that individual with hatched offspring in the breeding season following the period of data collection showed higher digestive efficiency than those failing to hatch goslings. This suggests that it might be important for a goose to be able to digest food efficiently at the beginning of the breeding season in order to store sufficient energy for egg laying.

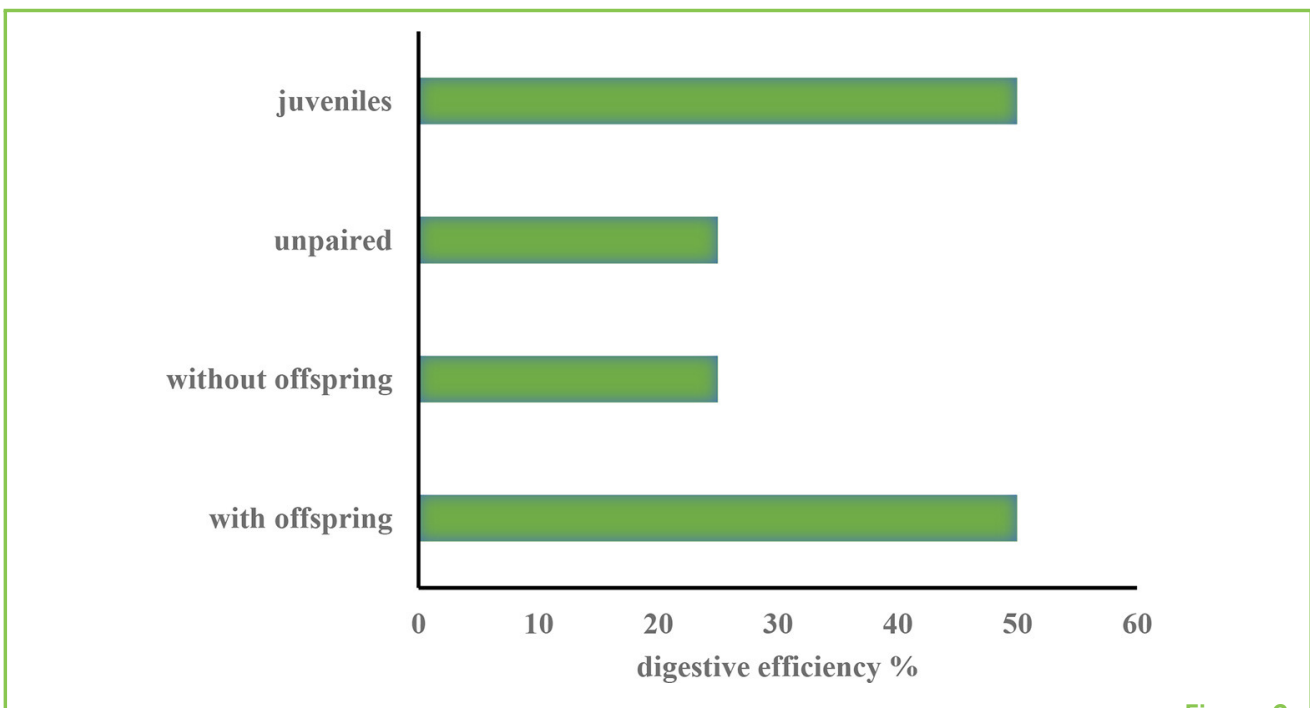

Figure 2

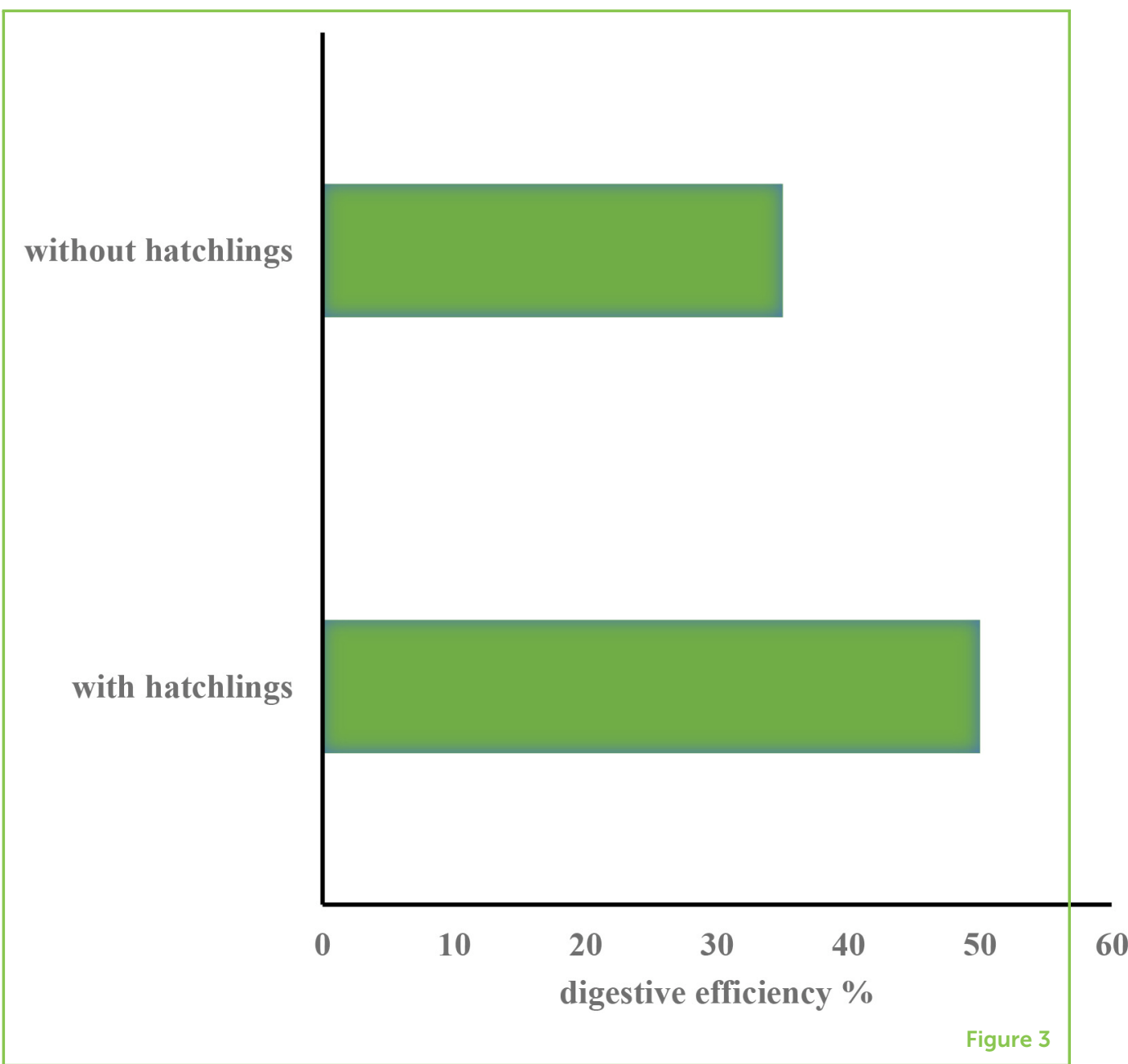

digestive efficiency and reproductive success. To find this out, further experimental studies would be needed.

So now you know that digestive efficiency is considered to be an indicator of the overall body condition of an individual. Furthermore, 
you know that the physical constitution and possibly also the reproductive success of an individual are supported by stable social relationships. This is important for all social animal species because it shows that the social environment may influence an animal's well-being in both the short- and long-term, by affecting breeding success.

\section{ACKNOWLEDGMENTS}

Many colleagues were contributing to the success of our study. We gratefully acknowledge Lara laiza and Verena Puehringer-Sturmayr for helping in the field. Carla Fabro, Chiara Sarnataro, and Federico Mason helped in the lab. Josef Hemetsberger, Kurt Kotrschal, and Stefano Filacorda provided the scientific assistance. Helene Vesely draw the goose for Figure 1.

\section{ORIGINAL SOURCE ARTICLE}

Frigerio, D., Kotrschal, K., Fabro, C., Puehringer-Sturmayr, V., laiza, L., Hemetsberger, J., et al. 2018. Social context modulates digestive efficiency in graylag geese (Anser anser). Sci. Rep. 8:16498. doi: 10.10 38/s41598-018-34337-3

\section{REFERENCES}

1. Wingfield, J. C. 2005. The concept of allostasis: coping with a capricious environment. J. Mammal. 86:248-54. doi: 10.1644/BHE-004.1

2. Frigerio, D., Hemetsberger, F., and Wascher, C. A. F. 2019. How having a partner and a family influences the stress response of graylag geese. Front. Young Minds 7:68. doi: 10.3389/frym.2019.00068

3. Lima-Ojeda, J, Rupprecht, R., and Baghai, T. 2019. Happy gut bacteria, happy brain: the microbiota-gut-brain axis. Front. Young Minds 7:15. doi: 10.3389/ frym.2019.00015

4. Black, J. M., Prop, J., and Larsson, K. 2007. Wild Goose Dilemmas: Population Consequences of Individual Decisions in Barnacle Geese. Groningen: Branta Press.

SUBMITTED: 03 March 2020; ACCEPTED: 27 August 2020; PUBLISHED ONLINE: 30 October 2020.

EDITED BY: Stuart Semple, University of Roehampton London, United Kingdom

CITATION: Gegendorfer G and Frigerio D (2020) How Having a Family Improves Digestion in Social Geese. Front. Young Minds 8:540008. doi: 10.3389/frym.2020. 540008 
CONFLICT OF INTEREST: The authors declare that the research was conducted in the absence of any commercial or financial relationships that could be construed as a potential conflict of interest.

COPYRIGHT () 2020 Gegendorfer and Frigerio. This is an open-access article distributed under the terms of the Creative Commons Attribution License (CC BY). The use, distribution or reproduction in other forums is permitted, provided the original author(s) and the copyright owner(s) are credited and that the original publication in this journal is cited, in accordance with accepted academic practice. No use, distribution or reproduction is permitted which does not comply with these terms.

\section{YOUNG REVIEWER}

\section{FRESIA, AGE: 11}

I love science and math, but I am not a fan of history and geography. My big passion is animals. I have a snake named Sacha Jr., and a rabbit named Luna, and I love to raise silkworms and search for lizards and other animals in the wild. I am also learning to ride horses and I love using creativity to make crafts.

\section{AUTHORS}
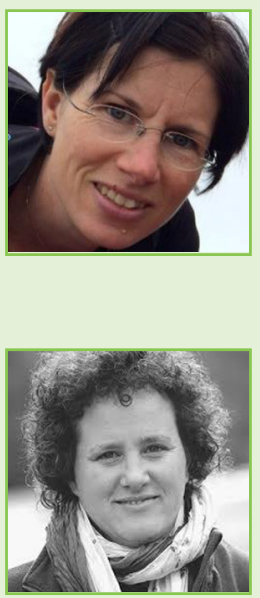

\section{GUDRUN GEGENDORFER}

Gudrun Gegendorfer is a biologist and is particularly interested in knowledge transfer. She is involved in the Citizen Science projects about behavioral research on graylag geese and northern bald ibises, which are carried out at the Konrad Lorenz Research Center. There, she supervises the Citizen Scientists, leads introductory workshops, and supports the participants in their tasks.

\section{DIDONE FRIGERIO}

Didone Frigerio is a behavioral biologist. Her main interest is the relationship between sociality and the processes that are going on inside the body (physiology) in group-living birds. She loves to work with graylag geese, even though northern bald ibises have also caught her attention recently. She applies citizen science by involving pupils and citizens in her behavioral research. *didone.frigerio@univie.ac.at 